University of Nebraska - Lincoln

DigitalCommons@University of Nebraska - Lincoln

Faculty Publications, Department of Psychology

Psychology, Department of

3-9-2001

\title{
An Exploration of Factors Related to Deviant Sexual Arousal Among Juvenile Sex Offenders
}

\author{
William D. Murphy \\ University of Tennessee Health Science Center \\ Mary R. Haynes \\ University of Tennessee Health Science Center \\ David DiLillo \\ University of Nebraska-Lincoln, ddilillo@unl.edu \\ Elaine Steere \\ University of Tennessee Health Science Center
}

Follow this and additional works at: https://digitalcommons.unl.edu/psychfacpub

Part of the Psychiatry and Psychology Commons

Murphy, William D.; Haynes, Mary R.; DiLillo, David; and Steere, Elaine, "An Exploration of Factors Related to Deviant Sexual Arousal Among Juvenile Sex Offenders" (2001). Faculty Publications, Department of Psychology. 204.

https://digitalcommons.unl.edu/psychfacpub/204

This Article is brought to you for free and open access by the Psychology, Department of at DigitalCommons@University of Nebraska - Lincoln. It has been accepted for inclusion in Faculty Publications, Department of Psychology by an authorized administrator of DigitalCommons@University of Nebraska - Lincoln. 


\title{
An Exploration of Factors Related to Deviant Sexual Arousal Among Juvenile Sex Offenders
}

\author{
William D. Murphy \\ Department of Psychiatry, University of Tennessee Health Science Center \\ Mary R. Haynes \\ Department of Psychiatry, University of Tennessee Health Science Center \\ David DiLillo \\ Department of Psychology, University of Nebraska-Lincoln \\ Elaine Steere \\ Department of Biostatistics and Epidemiology, University of Tennessee Health Science Center
}

\begin{abstract}
To date, there has been limited literature on the measurement of sexual arousal in adolescent sex offenders. The data that exist have been somewhat mixed in terms of factors related to deviant sexual arousal in this group. The present study, with 71 adolescent sex offenders, investigates the relationship between offender and offense characteristics, including gender of victim, history of sexual abuse, history of physical abuse, race, and interactions between these factors in the prediction of physiologically measured sexual arousal to deviant and nondeviant stimulus categories. A number of variables significantly predicted sexual arousal. The most consistent predictors were gender of victim, race, the interaction of race and gender of victim, and to some extent the interaction of offender abuse history and gender of victim. Caucasian subjects tended to respond more than African American subjects did, and this has not been reported previously in the literature. The data are discussed in terms of consistency with other literature, suggesting that those juvenile offenders who target male victims and have been abused themselves may be a high risk group. Limitations of this study are also addressed.
\end{abstract}

Key Words: juvenile sex offenders, plethysmography, history of abuse, victim gender.

\section{INTRODUCTION}

Sexual responding has been studied extensively in adult perpetrators (see Murphy \& Barbaree, 1994, for a review). Although little is known about the arousal preferences of adolescent perpetrators, there is at least suggestive evidence that 
deviant arousal may play a role in juvenile offending. Schram, Milloy, and Rowe (1991) and Worling and Curwen (2000) found that self-reported deviant arousal was related to offender recidivism among adolescents. Given this likelihood, knowledge of the relationship between specific offender characteristics (e.g., offenders' own sexual and physical abuse history, gender of victims, etc.) and the juveniles' own arousal preferences may help elucidate the developmental pathways leading to sexual perpetration.

Phallometric assessment is one of the most commonly used methods of measuring deviant arousal in adult males (Knopp, Freeman-Longo, \& Stevenson, 1992). However, to date phallometrically measured data for juveniles are limited, and information relating deviant arousal to specific offender characteristics is particularly sparse. In one of the few studies, to examine factors associated with juvenile erectile responding to inappropriate sexual stimuli, Becker, Hunter, Stein, and Kaplan (1989) found that adolescent offenders with a history of sexual victimization, who had also sexually abused male children, showed greater deviant arousal to audio cues than did those who had not been abused or whose victims were young girls. Becker, Kaplan, and Tenke (1992) also utilized audio cues to examine responding in 83 male adolescent sex offenders. Results revealed that abused offenders showed higher levels of arousal overall, to both deviant and nondeviant stimuli. In contrast, Hunter, Goodwin, and Becker (1994), using a deviance quotient (derived from a ratio of deviant to nondeviant sexual interest), failed to find a strong relationship between prior sexual victimization and deviant arousal in either of the two samples of 44 and 54 juvenile sex offenders. They did find that those perpetrators who had abused only males showed greater deviant arousal than did those who had abused female victims only or a combination of both genders. Kaemingk, Koselka, Becker, and Kaplan (1995) also found that age correlated with arousal, with younger subjects evidencing more arousal. Because the few existing findings have been inconsistent, there is need for further investigation of these relationships.

The present study is intended to augment the limited data in this area by exploring offender characteristics as possible predictors of arousal in a different sample of adolescent perpetrators. Specifically, history of sexual victimization, history of physical abuse, gender of victim, age, and number of victims were selected for study in relationship to phallometrically measured arousal. Because a previous study (Cooper, Murphy, \& Haynes, 1996) found differences in reports of history of sexual abuse between Caucasian and African American subjects, race was also chosen as a variable for inclusion.

\section{METHOD}

\section{Participants}

Participants were 71 male adolescent sex offenders who were evaluated at the Special Problems Unit, Department of Psychiatry, University of Tennessee
Health Science Center, a university-based evaluation and treatment program for sexual offenders. The mean age of the participants was 15.2 years. Participants had completed an average of 8.4 years of schooling. The mean age at which subjects had committed their first offense was 13.2 years, whereas the mean number of known victims for each perpetrator was 4.2. Of the 71 participants, $47.1 \%$ were Caucasian and the remaining 52.9\% were African American. Twenty-seven participants were identified as having been sexually abused, and 30 had a history of physical abuse. Forty-five subjects abused female victims, 11 abused male victims, and 15 abused both male and female victims. In all but three cases, victims were at least 5 years younger than the offender was. In two cases, the victim was 4 years younger, and in one case, he or she 2 years younger.

\section{Measures}

\section{Abuse and Perpetration History}

A structured history was taken on each participant as part of the University of Tennessee Health Science Center Sex Offender Program intake assessment. The history is collected from patients and family members who are present, and is supplemented by official records when obtainable. The history focuses on social and family background, educational history, criminal and delinquent behavior, past psychological and psychiatric problems, prior drug and alcohol use, peer and family relationships, and sexual history, including deviant and nondeviant behavior. From these histories, demographic-, offense-, and abuse-specific variables were coded for analysis. Data were included for all subjects for whom there was an unequivocal history regarding the presence or absence of physical abuse or sexual abuse. Sexual abuse was defined as any hands-on offense involving either a clear age difference of at least 5 years between the offender and the patient, or where there was clear indication of the use of coercion. One subject had missing data for history of sexual abuse but had data regarding physical abuse, whereas one subject had missing data for history of physical abuse. For analysis purposes, subjects with both female and male victims were combined with subjects with only male victims.

\section{Sexual Arousal}

Subjects underwent psychophysiological assessment of sexual arousal. This involved the use of a small circumferential-type transducer placed upon the penis by subjects to assess erectile response. In the privacy of the laboratory, each participant listened to a series of 2-min audiotaped descriptions of various sexual interactions that varied with respect to age, gender of victim, and the presence of physical force. These stimuli were developed by Becker, Hunter, Goodwin, Kaplan, and Martinez 
(1992) and have demonstrated fairly good test-retest reliability. The audio cues represented various types of sexual behaviors in which juvenile sex offenders may typically engage. Each participant received two complete presentations of 21 cues presented in a random order: (1) male age 10-11 consenting, (2) male peer consenting, (3) incest with male child, (4) male age 6-7 with force, (5) male age 10-11 with force, (6) male peer with force, (7) female age 10-11 consenting, (8) female peer consenting, (9) incest with female child, (10) female age 6-7 with force, (11) female age 10-11 with force, (12) female peer with force, (13) adult sex with force, (14) exhibitionism, (15) frottage, (16) voyeurism, (17) adult heterosexual, and (18) adult homosexual. The following nonsexual interactions were also presented: (19) male assault, (20) female assault, and (21) a neutral social interaction. To avoid fatigue, the stimuli were divided in half and presented in two laboratory sessions separated by at least $2 \mathrm{hr}$. The second set of stimuli presentations was presented on a second day, generally $24 \mathrm{hr}$ later, again in two separate sessions. Because of the large number of stimuli, six of the stimuli were chosen a priori as variables for this study. These included male and female peer consenting stimuli, male and female peer rape stimuli, and male and female child rape stimuli. These stimuli were those most similar to the stimuli used in previous studies.

Erection responses during the evaluation were measured via a Grass Model 7 polygraph, using a Barlow strain gauge (Barlow, Becker, Leitenberg, \& Agras, 1970) and were recorded as changes (in $\mathrm{mm}$ ) in penile circumference from a flaccid state. These readings were later converted to scores representing a percent of full erection, which had been calculated during a calibration period occurring prior to the actual evaluation or based on the highest response during stimulus presentation. Interstimulus interval was a minimum of $30 \mathrm{~s}$ or until subject returned to within 3-5 $\mathrm{mm}$ of baseline. These procedures represent commonly utilized and widely accepted methods of evaluating offenders' sexual arousal patterns (Murphy \& Barbaree, 1994). Three subjects had missing data for the arousal assessment.

\section{Procedures}

Participants were referred for evaluation by a number of sources, including Juvenile Court, child protective services, attorneys, and mental health professionals. Most of the evaluations took place over a 2-day period, with the vast majority being completed within 1 week. After providing informed consent, participants and their families, when available, were administered the structured interview by a doctoral-level psychologist (a few participants were seen by psychology interns or postmasters doctoral students). The interviews were followed by the psychophysiological evaluations of arousal. Each subject had a total of four laboratory sessions, each lasting approximately $1 \mathrm{hr}$ over a 2-day period. Between evaluations, participants also completed a number of standardized inventories, data which are not relevant to the present study, and therefore are not reported here.

\section{RESULTS}

In a previous study, we found that sexually abused subjects differed from non-sexually abused subjects on certain demographic variables (Cooper et al., 1996). Therefore, preliminary analyses investigated some of these variables, and Table I provides subject variables for sexually abused and nonsexually abused subjects. As can be seen, sexually abused subjects differed from nonsexually abused subjects in terms of race and age of onset of their offending. Sexually abused subjects began their offending 1.6 years earlier than nonsexually abused subjects did. Also, fewer African American subjects admitted to histories of sexual abuse than Caucasian subjects did. Sixty-one percent of the Caucasian subjects versus $19 \%$ of the African American subjects reported a history of sexual abuse. Although not included in the table, similar results were found for history of physical abuse. For history of physical abuse, $62 \%$ of Caucasian subjects reported a history of physical abuse as compared to $26 \%$ of African American subjects $\left(\chi^{2}=\right.$ $9.29, d f=1, p=.002$ ). Although not reaching significance, Table I also indicates that approximately $48 \%$ of those subjects who had a history of sexual abuse had at least one male victim, whereas only $30 \%$ of the nonsexually abused subjects had a history of male victims.

As a preliminary analysis, correlations were conducted between each of the six sexual arousal variables and selected subject variables. As can be seen in Table II, the strongest relationships with the sexual arousal measures were gender of victim and race. Gender of victim was negatively correlated with the male peer

Table I. Comparison of Sexually Abused and Nonsexually Abused Subjects on Selected Subject Variables

\begin{tabular}{lcc}
\hline Subject variable & Sexually abused $(N=27)$ & Nonsexually abused $(N=43)$ \\
\hline Age & & \\
$X$ & 14.9 & $15.2^{a}$ \\
SD & 2.41 & 1.24 \\
Age of onset & 12.2 & $13.8^{b}$ \\
$\quad X$ & 2.77 & 2.31 \\
SD & 20 & \\
Race & 7 & $13^{c}$ \\
$\quad$ Caucasian & & 30 \\
$\quad$ African American & 5.59 & $3.33^{a}$ \\
Number of victims & 12.36 & 6.93 \\
$\quad X$ & & \\
SD & 13 & $13^{a}$ \\
Gender of victim & 14 & 30 \\
$\quad$ At least one & & \\
Male & & \\
Female & & \\
${ }^{a}$ Nonsignificant. & \\
${ }^{b} t(66)=2.6, p<.01$. & & \\
${ }^{c} \chi^{2}=12.8, p<.01$. & &
\end{tabular}


Table II. Correlations and Significance Levels Between Arousal Measures and Subject Variables

\begin{tabular}{|c|c|c|c|c|c|c|}
\hline \multirow[b]{2}{*}{ Variable } & \multicolumn{6}{|c|}{ Sexual stimuli } \\
\hline & $\begin{array}{c}\text { Male peer } \\
\text { consent }\end{array}$ & $\begin{array}{l}\text { Male child } \\
\text { rape }\end{array}$ & $\begin{array}{l}\text { Male peer } \\
\text { rape }\end{array}$ & $\begin{array}{l}\text { Female peer } \\
\text { consent }\end{array}$ & $\begin{array}{l}\text { Female } \\
\text { child rape }\end{array}$ & $\begin{array}{l}\text { Female } \\
\text { peer rape }\end{array}$ \\
\hline $\begin{array}{l}\text { History of physical } \\
\text { abuse }\end{array}$ & .13 & -.11 & .06 & $-.25^{*}$ & .07 & -.07 \\
\hline $\begin{array}{l}\text { History of sexual } \\
\text { abuse }\end{array}$ & .11 & .21 & .17 & -.01 & .16 & .08 \\
\hline Female victim only & $-.38^{* * *}$ & $-.31^{* *}$ & $-.38^{* * *}$ & -.10 & $-.30^{* *}$ & -.12 \\
\hline African American & $-.25^{*}$ & $-.30^{* *}$ & $-.29^{*}$ & $-.24^{*}$ & $-.25^{*}$ & $-.46^{* * *}$ \\
\hline Age & .12 & .08 & .18 & .12 & .01 & .04 \\
\hline $\begin{array}{l}\text { Total number of } \\
\text { victims }\end{array}$ & .02 & .10 & .10 & .03 & -.06 & .11 \\
\hline
\end{tabular}

consent stimuli, the male child rape stimuli, the male peer rape stimuli, and the female child rape stimuli. Race was negatively correlated with all the arousal measures, suggesting that African American subjects showed less responding to all stimuli as compared to Caucasian subjects. In terms of gender of victim, the results indicate that those subjects with any male victims tended to respond more than those subjects with female victims. Subjects with a history of physical abuse showed a negative correlation only to the female peer consent stimuli, suggesting that subjects who had been physically abused showed less response to this stimuli than did those who had not been physically abused. There was only one marginally significant finding $(r=.21, p=.08)$ for history of sexual abuse for the male child rape stimuli. There was no relationship between any of the arousal measures and age or total number of victims.

To investigate the relationship between offender and offense characteristics and deviant sexual arousal, multiple regressions were conducted. Because this was seen as an exploratory study, and there are limited data in the literature, a decision was made to conduct separate multiple regression analyses on each of the six arousal measures. It was felt that there might be different predictors for male-versus-female stimuli, force-versus-nonforce stimuli, and child-versus-peer stimuli. For the initial set of multiple regressions, the independent variables chosen were history of physical abuse, history of sexual abuse, gender of victim, and race. Because age and total number of victims did not correlate with any of the sexual arousal measures, these variables were dropped to reduce the number of independent variables. Although there were limited relationships between history of physical abuse and history of sexual abuse, these variables were maintained because of their frequent mention in the literature as having possible etiological significance in sex offending.

Beta weights and the multiple $R^{2}$ for these analyses are included in Table III. As can be seen, five of the multiple $R$ 's were significant, whereas the analy-
Table III. Multiple Regression Results and Significance Levels for History of Physical Abuse, History of Sexual Abuse, Gender of Victim, and Race Predicting the Six Sexual Arousal Measures

\begin{tabular}{lcccccc}
\hline & $\begin{array}{c}\text { Male peer } \\
\text { consent }\end{array}$ & $\begin{array}{c}\text { Male child } \\
\text { rape }\end{array}$ & $\begin{array}{c}\text { Male peer } \\
\text { rape }\end{array}$ & $\begin{array}{c}\text { Female peer } \\
\text { consent }\end{array}$ & $\begin{array}{c}\text { Female } \\
\text { child rape }\end{array}$ & $\begin{array}{c}\text { Female } \\
\text { peer rape }\end{array}$ \\
\hline $\begin{array}{l}\text { History of physical } \\
\quad\end{array}$ & $-.01^{a}$ & $-.34^{* *}$ & -.13 & $-.39^{* *}$ & -.01 & $-.26^{*}$ \\
$\quad \begin{array}{l}\text { abuse } \\
\text { History of sexual }\end{array}$ & .01 & .14 & .10 & -.03 & .04 & .06 \\
$\quad$ abuse & & & & & & \\
Female victim only & $-.32^{* *}$ & $-.29^{*}$ & $-.32^{* *}$ & -.09 & $-.27^{*}$ & -.05 \\
African American & -.16 & $-.29^{*}$ & -.20 & $-.36^{* *}$ & -.28 & $-.56^{* * *}$ \\
Multiple $R^{2}$ & $.15^{*}$ & $.24^{* *}$ & $.18^{*}$ & $.19^{*}$ & .13 & $.27^{* * *}$ \\
\hline $\begin{array}{l}a \\
\text { Beta weigls }\end{array}$ & & & & & &
\end{tabular}

${ }^{a}$ Beta weights.

${ }^{*} p<.05 .{ }^{* *} p<.01 .^{* * *} p<.001$

ses for the female child rape stimuli was marginally significant $(p=.06)$. Thirteen to twenty-seven percent of the variance was accounted for depending on the stimuli. The best predictions were for the male child rape stimuli and the female peer rape stimuli. History of physical abuse was a significant predictor for three of the arousal stimuli, gender of victim for four of the stimuli, and race for three of the stimuli. A history of sexual abuse was not a significant predictor for any of the sexual arousal measures. As with the correlations, physically abused subjects and African American subjects showed lower responding than did nonphysically abused subjects and Caucasian subjects. Subjects with male victims showed more responding than did those with female victims. However, it should be noted that although a history of physical abuse was a relatively strong predictor, the actual mean difference between groups was small. For the male child rape stimuli, female peer consent stimuli, and female peer rape stimuli, the respective differences between groups were $5 \%, 12 \%$, and $3 \%$ of a full erection.

Because the initial multiple regression only looked at main effects, it is possible that there are interactions between variables that improve prediction. Therefore, each pair of main effects and their interactions were analyzed for each of the six arousal measures. Results of these interaction analyses indicated that the Gender of Victim $\times$ Race interaction was significant for three of the sexual arousal measures, and Gender of Victim $\times$ History of Sexual Abuse was basically significant for two of the arousal measures. In addition, when the interaction analyses were run, history of sexual abuse was significant for three of the arousal measures. History of Physical Abuse $\times$ Race was only significant for the female rape stimuli. Tables IV-VI present this data. Tables IV and V present all stimulus categories, including means and significance level. Because only one variable was significant for the History of Sexual Abuse $\times$ Race, only that variable is presented in Table VI. Because of the correlation between main effect and the interaction, significance levels of predictors rather than beta weights are presented. Because of the inter-correlation of the main effect and interaction, significant main effects cannot be clearly interpreted. 
Table IV. Mean Percent Erections and Multiple Regression Results for Gender of Victim $\times$ Race

\begin{tabular}{|c|c|c|c|c|c|c|}
\hline & $\begin{array}{c}\text { Male peer } \\
\text { consent }\end{array}$ & $\begin{array}{l}\text { Male child } \\
\text { rape }\end{array}$ & $\begin{array}{l}\text { Male peer } \\
\text { rape }\end{array}$ & $\begin{array}{c}\text { Female peer } \\
\text { consent }\end{array}$ & $\begin{array}{l}\text { Female } \\
\text { child rape }\end{array}$ & $\begin{array}{l}\text { Female } \\
\text { peer rape }\end{array}$ \\
\hline & \multicolumn{6}{|c|}{ Mean percent erection } \\
\hline \multicolumn{7}{|l|}{ Group } \\
\hline $\begin{array}{l}\text { Male victim- } \\
\text { Caucasian }\end{array}$ & 43.1 & 43.2 & 45.8 & 59.7 & 56.5 & 58.3 \\
\hline $\begin{array}{l}\text { Male victim- } \\
\text { African American }\end{array}$ & 24.8 & 21.1 & 20.2 & 37.3 & 37.1 & 23.6 \\
\hline $\begin{array}{l}\text { Female victim- } \\
\text { Caucasian }\end{array}$ & 19.7 & 22.9 & 18.8 & 48.4 & 35.9 & 46.8 \\
\hline \multirow[t]{2}{*}{$\begin{array}{l}\text { Female victim- } \\
\text { African American }\end{array}$} & 18.1 & 20.4 & 18.8 & 44.4 & 32.5 & 33.7 \\
\hline & \multicolumn{6}{|c|}{ Significance levels of predictors and multiple $R^{2}$} \\
\hline \multicolumn{7}{|l|}{ Variables } \\
\hline Female victim only & .013 & .009 & .001 & .100 & .048 & .047 \\
\hline African American & .046 & .011 & .002 & .040 & .08 & .002 \\
\hline Interaction & ns & .041 & .009 & ns & ns & .04 \\
\hline Multiple $R^{2}$ & $.21^{* *}$ & $.21^{* *}$ & $.27^{* * *}$ & .10 & $.25^{*}$ & $.26^{* * *}$ \\
\hline
\end{tabular}

${ }^{*} p<.05 .{ }^{* *} p<.01 .{ }^{* *} p<.001$.

Table V. Mean Percent Erections and Multiple Regression Results for Gender of Victim $\times$ History of Sexual Abuse

\begin{tabular}{|c|c|c|c|c|c|c|}
\hline & $\begin{array}{c}\text { Male peer } \\
\text { consent }\end{array}$ & $\begin{array}{l}\text { Male child } \\
\text { rape }\end{array}$ & $\begin{array}{l}\text { Male peer } \\
\text { rape }\end{array}$ & $\begin{array}{c}\text { Female peer } \\
\text { consent }\end{array}$ & $\begin{array}{c}\text { Female } \\
\text { child rape }\end{array}$ & $\begin{array}{l}\text { Female } \\
\text { peer rape }\end{array}$ \\
\hline & \multicolumn{6}{|c|}{ Mean percent erection } \\
\hline \multicolumn{7}{|l|}{ Group } \\
\hline Male victim no-abuse & 32.3 & 24.2 & 28.0 & 50.2 & 38.9 & 42.4 \\
\hline Female victim-no abuse & 19.3 & 22.2 & 19.7 & 46.6 & 35.6 & 37.7 \\
\hline Male victim-abuse & 38.9 & 43.8 & 42.5 & 51.2 & 57.8 & 46.3 \\
\hline Female victim-abuse & 17.8 & 19.8 & 17.3 & 44.1 & 31.8 & 40.1 \\
\hline & \multicolumn{6}{|c|}{ Significance levels of predictors and multiple $R^{2}$} \\
\hline \multicolumn{7}{|l|}{ Variables } \\
\hline $\mathrm{Hx}$ of abuse & ns & .012 & .069 & ns & .037 & ns \\
\hline Female victim only & .069 & ns & ns & ns & ns & ns \\
\hline Interaction & ns & .026 & ns & ns & .057 & ns \\
\hline Multiple $R^{2}$ & $.15^{*}$ & $.18^{* *}$ & $.19 * *$ & .02 & $.15^{*}$ & .02 \\
\hline
\end{tabular}

Post hoc tests using Fisher's least significance difference procedure were used to further analyze significant interactional effects. For the gender of victim $\times$ race interactions (Table IV), the results indicate that for the male child rape stimuli and the male peer rape stimuli, Caucasian subjects with male victims showed significantly more responding than did the other rape stimuli, the follow-up post
Table VI. Mean Percent Erections and Multiple Regression Results for History of Physical Abuse $\times$ Race for the Female Peer Rape Stimuli

Female peer rape stimuli

Mean percent erection

Group

No physical abuse-Caucasian

No physical abuse-African American $\quad 31.6$

Physical abuse-Caucasian $\quad 42.8$

Physical abuse-African American 29.5

Significance levels of predictors and multiple $R^{2}$

Variables

History of physical abuse

African American $\quad .0001$

Interaction $\quad .046$

Multiple $R^{2} \quad .30^{*}$

$* p<.001$

hoc analysis indicated that the two Caucasian groups differed significantly from the two African American groups but did not differ from each other.

For the Gender of Victim $\times$ History of Sexual Abuse Results (Table V), follow-up tests indicated that for the male child rape stimuli and the female child rape stimuli those individuals who had male victims and had been sexually abused themselves showed significantly greater responding than did the other groups ( $p<$

$.05)$. For the History of Physical Abuse $\times$ Race interaction (Table VI) for the female rape stimuli, nonphysically abused Caucasian subjects showed significantly more responding than the other three groups did $(p<.05)$. Physically abused Caucasian subjects responded significantly $(p<.05)$ more than the non-physically abused African American groups did and marginally significantly more than the physically abused African American group did $(p=.08)$.

\section{DISCUSSION}

The initial regression analyses without interactions and the correlational analyses suggested that the strongest predictors of the sexual arousal measures were sex of victim and race. Although history of physical abuse was a significant predictor for three of the arousal measures, inspection of means suggested that the only meaningful differences were for the female peer consent stimuli. The results for the gender of victim variable are, in general, consistent with the results of Becker et al. (1989) and Hunter et al. (1994), who tended to find higher responding in those subjects who had abused male subjects. In the present study, this was true for all of the male sexual stimuli and child rape stimuli but not for female peer stimuli. 
The relationship of history of sexual abuse and the interaction of history of sexual abuse and gender of victim to deviant sexual arousal is somewhat complex. In the initial analyses, there was little relationship between history of sexual abuse and any of the arousal measures. However, when the interaction of history of sexual abuse and gender of victim was added, history of sexual abuse and the interaction with gender of victim were significant predictors for both of the child rape stimuli. Those subjects who had been abused and who chose at least one male victim evidenced the highest levels of deviant arousal. There was a similar trend for the male peer rape stimuli, but the interaction did not reach significance. Previous results have been inconsistent for this interaction. Becker et al. (1989), using a different stimulus set, found similar results, whereas Hunter et al. (1994) did not find this interaction. Becker et al. (1992) found that abused offenders showed higher levels of arousal to both deviant and nondeviant stimuli, whereas this was not the case in the current study. However, there were some procedural differences. In the Hunter study, stimuli were presented only once, whereas in the current study stimuli were presented twice possibly increasing the reliability of the measures in this study. This may also be the reason that no relationship was found between arousal measures and age in the current study, whereas this relationship was found in the study by Kaemingk et al. (1995). Whether the current study was more reliable because of more stimulus presentations will have to be answered by further research. Hunter et al. (1994) also used pedophile indices as the dependent measure, whereas the current study looked at response to specific stimuli. However, inspection of the means suggested that pedophile indices of the sexually abused subjects who chose at least one male victim would be almost twice as large as any of the other groups.

However, all of the above results may be limited to Caucasian subjects. As was found by Cooper et al. (1996), African American subjects less frequently reported a history of sexual abuse, whereas in the current study, they less frequently reported a history of physical abuse. In addition, African American subjects tended to show significantly lower arousal to most of the stimuli presented. The reason for this finding is unclear, and there is limited literature that addresses ethnic or racial differences in laboratory sexual responding or in terms of history of sexual and physical abuse. It cannot be determined from the current data whether these results represent actual difference in histories of abuse between the Caucasian and African American subjects in this population or represent underreporting by the African American subjects. The majority of interviewers were Caucasian, and it is possible that African American subjects felt less comfortable disclosing their histories of abuse to the interviewers. The lower responding in the laboratory across stimuli also has no clear explanation. It is not clear whether the audio cues used were inherently less arousing to African American subjects or whether there is some interaction between cultural background and the overall assessment process that leads to more suppression in the laboratory for nonmajority culture subjects.
To the extent that the presence of deviant sexual arousal is associated with higher risk as indicated by Hanson and Bussière (1998), this study is consistent with other nonarousal data. First, subjects who abuse male victims are at higher risk for recidivism (Hanson \& Bussière, 1998), and it is this group of subjects who show the highest arousal to deviant stimuli. However, within the adolescent literature, the relationship between victim gender and sexual reoffending is less clear. Smith and Monastersky (1986) and Långström and Grann (2000) both found that a history of male victims was related to recidivism, whereas this was neither found by Worling and Curwen (2000) nor was it found by Rasmussen (1999). However, there were only a small number of recidivists (13) in the Rasmussen study.

In the adult literature, it may be that choice of male victims is more highly correlated with a set deviant sexual attraction to male children than it is in the adolescent population. In the adolescent population, those who choose male victims may be a more heterogeneous group, with some having an actual set sexual attraction to young children and others choosing male victims based on opportunity and not preference. Actual measures of sexual attraction to young males might be a better predictor of reoffense than gender of victim. The current study is also limited in that subjects were coded in terms of having any male victim and the sample size was too small to look at those who only chose male victims. There is a need for future studies with a larger sample of adolescents who target only male children.

As noted, the results for the history of sexual abuse variable were somewhat mixed in this study and only tentatively suggest that an interaction between history of sexual abuse and the choosing of at least one male victim are related to deviant sexual arousal. However, other data may indirectly suggest that those subjects who are sexually abused may be a high risk group. First, the current study found that those who had been sexually abused had an earlier onset of their offending history. Similarly, Cooper et al. (1996), in a study with a larger group of subjects, found that those subjects who had been abused also had an early onset of their sex offending, had more victims, and evidenced slightly more psychopathology and poorer social skills. Similar findings have been reported by Becker and Stein (1991), Kaufman, Hilliker, and Daleiden (1996), and Richardson, Kelly, Bhate, and Graham (1997). Kaufman et al. (1996) found that those subjects who were abused more often chose male victims and there was a similar trend in this current study. However, it should be noted that Hanson and Bussière (1998) did not find a relationship between recidivism and history of sexual abuse in adult offender populations. It may be that history of sexual abuse only indirectly relates to recidivism in predisposing abused subjects to choose male victims and to develop deviant sexual arousal patterns. This hypothesis is not inconsistent with recent work by Johnson and Knight (2000), showing that sexual abuse is a precursor to sexual compulsivity and sexual coercion in juvenile sexual offenders. 
There are a number of limitations to the current study. First, as noted, the differences between African American and Caucasian subjects complicate the interpretation of the current results. The sample sizes in this preliminary study were too small to analyze Caucasian and African American subjects separately or to look at three-way interactions between race and the other variables. Therefore, the findings of the current study seem most applicable to Caucasian subjects. Unfortunately, there is an extreme lack of data on ethnic or racial differences in arousal measures in either the adult or adolescent population. It seems, given the results of the current study, that investigators need to begin looking at potential subgroup differences to determine reliability and validity data in non-Caucasian groups.

Another major problem, as with many studies of this type, is that history of sexual abuse and physical abuse are many times based on self-report. In some cases, official data were available to verify histories of abuse in subjects, but many times no such official records were available. Therefore, subjects could have over-or underreported their histories of abuse. In addition, although some of the analyses accounted for significant proportions of the variance, there are still significant proportions of the variance not accounted for in the results. Further studies will need to address other factors potentially related to sexual arousal in adolescent populations such as familial relationships (Hunter et al., 1994) and potential amount of aggression in the offense. Further studies are also needed to compare more directly offenders against children and offenders against peers. Also, the current study had a relatively small sample size with multiple exploratory analyses, leading to the possibility of chance results. Further replication with larger sample sizes are needed.

Although assessment of sexual arousal through plethysmography remains somewhat controversial in adolescents, the current data add further preliminary validity to the technique. The arousal measures in this study do seem to separate subgroups, and the subgroups have the potential of being related to recidivism and treatment needs. In addition, the study also provides further evidence that male pedophilia may have an early onset. Although again quite preliminary, the data would suggest that those offenders who have been victims of sexual abuse and those offenders who target male victims may need to receive priority for intensive treatment efforts. However, this should not be interpreted to mean that all victims of sexual abuse are at risk for sexual offending as this is clearly not the case.

\section{REFERENCES}

Barlow, D. H., Becker, R., Leitenberg, H., \& Agras, W. S. (1970). A mechanical strai gauge for recording penile circumference change. Journal of Applied Behavior Analysis, 3, 73-76.

Becker, J. V., Hunter, J. A., Goodwin, D., Kaplan, M. S., \& Martinez, D. (1992). Test-retest reliability of audio-taped phallometric stimuli with adolescent sex offenders. Annals of Sex Research, 5, 45-51.
Becker, J. V., Hunter, J., Stein, R., \& Kaplan, M. S. (1989). Factors associated with erectile response in adolescent sex offenders. Journal of Psychopathology and Behavioral Assessment, 11, 353-362

Becker, J. V., Kaplan, M. S., \& Tenke, C. E. (1992). The relationship of abuse history, denial, and erectile response profiles of adolescent sexual perpetrators. Behavior Therapy, 23, 87-97.

Becker, J. V., \& Stein, R. M. (1991). Is sexual erotica associated with sexual deviance in adolescent males? International Journal of Law and Psychiatry, 14, 85-95.

Cooper, C. L., Murphy, W. D., \& Haynes, M. R. (1996). Characteristics of abused and nonabused adolescent sex offenders. Sexual Abuse: A Journal of Research and Treatment, 8, 105-119.

Hanson, R. K., \& Bussière, M. T. (1998). Predicting relapse: A meta-analysis of sexual offender recidivism studies. Journal of Consulting and Clinical Psychology, 66, 348362 .

Hunter, J. A., Goodwin, D. W., \& Becker, J. V. (1994). The relationship between phallometrically measured deviant sexual arousal and clinical characteristics in juvenile sexual offenders. Behavior Research and Therapy, 32, 533-538.

Johnson, G. M., \& Knight, R. A. (2000). Developmental antecedents of sexual coercion in juvenile sexual offenders. Sexual Abuse: A Journal of Research and Treatment, 12, $165-178$.

Kaemingk, K. L., Koselka, M., Becker, J. V., \& Kaplan, M. S. (1995). Age and adolescent sexual offender arousal. Sexual Abuse: A Journal of Research and Treatment, 7, 249-257.

Kaufman, K. L., Hilliker, D. R., \& Daleiden, E. L. (1996). Subgroup differences in the modus operandi of adolescent sexual offenders. Child Maltreatment, 1, 17-24.

Knopp, F. H., Freeman-Longo, R. L., \& Stevenson, W. S. (1992). Nationwide survey of adult sex offender treatment programs and models. Orwell, VT: Safer Society Press.

Långström, N., \& Grann, M. (2000). Risk for criminal recidivism among young sex offenders. Journal of Interpersonal Violence, 15, 855-871.

Murphy, W. D., \& Barbaree, H. E. (1994). Assessments of sexual offenders by means of erectile response: Psychometric properties and decision making. Brandon, VT: Safer Society Press.

Rasmussen, L. A. (1999). Factors related to recidivism among juvenile sex offenders. Sexual Abuse, A Journal of Research and Treatment, 11, 69-85.

Richardson, G., Kelly, T. P., Bhate, S. R., \& Graham, F. (1997). Group differences in abuser and abuse characteristics in a British sample of sexually abusive adolescents. Sexual Abuse, A Journal of Research and Treatment, 9, 239-257.

Schram, D. D., Milloy, C. D., \& Rowe, W. D. (1991). Juvenile sex offenders: A follow-up study of reoffense behavior. Olympia, WA: Washington State Institute for Public Policy.

Smith, W. R., \& Monastersky, C. (1986). Assessing juvenile sexual offenders' risk for reoffending. Criminal Justice and Behavior, 13, 115-140.

Worling, J. R., \& Curwen, T. (2000). Adolescent sexual offender recidivism: Success of specialized treatment and implications for risk prediction. Child Abuse and Neglect, 24 , 965-982. 